\title{
Risk of kidney health among returnee Nepali migrant workers: A survey of nephrologists
}

\author{
Nirmal Aryal', Arun Sedhain², Pramod R Regmi ${ }^{3}$, Radheshyam Krishna KC \\ Edwin van Teijlingen ${ }^{5}$
}

${ }^{1}$ Post-Doctoral Research Fellow, Department of Midwifery and Health Sciences, Faculty of Health and Social Sciences, Bournemouth University, United Kingdom, ${ }^{2}$ Nephrologist, Department of Medicine, Chitwan Medical College, Tribhuvan University, Bharatpur, Nepal, ${ }^{3}$ Senior Lecturer in International Health, Department of Nursing Science, Faculty of Health and Social Sciences, Bournemouth University, Bournemouth, United Kingdom; Visiting Research Fellow, Chitwan Medical College, Tribhuvan University, Nepal; Visiting Fellow, Datta Meghe Institute of Medical Sciences, Wardha, Maharashtra, India, ${ }^{4}$ Migration Health Officer, International Organization for Migration, Baluwatar, Kathmandu, Nepal, ${ }^{5}$ Professor of Reproductive Health Research, Department of Midwifery and Health Sciences, Faculty of Health and Social Sciences, Bournemouth University, Bournemouth, United Kingdom; Visiting Professor, Manmohan Memorial Institute of Health Sciences, Tribhuvan University, Bharatpur, Nepal; Visiting Professor, Nobel College, Pokhara University, Nepal

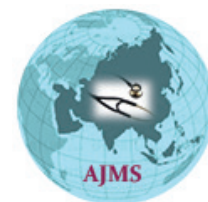

\section{A B S TRACT}

Background: Anecdotal reports suggest an increasing prevalence of kidney problems in returnee Nepali migrant workers from the Gulf countries and Malaysia. Aims and Objectives: This study aims to (a) explore the magnitude of the kidney health-related problems in returnee Nepali migrant workers; and, (b) assess the need for further scientific investigations. Materials and Methods: This was a self-administered survey of practicing nephrologists in Nepal. All 51 nephrologists working in Nepal (at the time of this study) were approached by email for anonymous participation using an online survey platform. Data were collected between December 2019 and February 2020. Descriptive statistics were generated for data analysis. Results: A total of 38 nephrologists completed the survey. Almost all their migrant patients were: younger than 40 years, males, from rural areas of Nepal, and had worked in Gulf countries or Malaysia. Most (92.1\%) of the respondents reported that the causes behind kidney-related problems of returnee migrant workers were of unknown etiology and less likely to be linked to traditional risk factors. Chronic kidney disease and glomerulonephritis were the most common kidney health-related problems. The vast majority of respondents $(76.3 \%)$ thought that the returnee migrant workers are at a higher risk of kidney-related problems than the general Nepali population. Conclusion: Nepali labor migrants in the countries of the Gulf and Malaysia could be at a higher risk of kidney health-related problems than the general Nepali population. Further rigorous scientific investigation is warranted to examine the kidney-health-related risk of Nepali migrant workers.

Key words: Acute kidney injury; Chronic kidney disease; Glomerulonephritis; Kidney failure; Kidney health; Migrants; Nepal

\section{INTRODUCTION}

The burden of chronic kidney disease (CKD) related morbidity and mortality is slowly rising. ${ }^{1,2}$ A systematic review estimated the global prevalence of CKD between $11 \%$ and $13 \%{ }^{3}$ with estimated annual mortality due to kidney disease between 5 and 10 million. ${ }^{4}$ Due to the lack of a national registry system, it is difficult to ascertain the prevalence of CKD in Nepal. However, a recent nation-wide cross-sectional survey in Nepal among 12,109 participants (aged 20 years or over) estimated the prevalence of CKD at $6.5 \%$ for men and $5.7 \%$ for women. ${ }^{5} \mathrm{~A}$ community-based study in Eastern Nepal estimated the prevalence of 10.6\% among population aged 20 years or above, ${ }^{6}$ most common causes of which are chronic glomerulonephritis (CGN), diabetes mellitus, and hypertension. ${ }^{7}$ 
Labor migration is an inevitable livelihood option for thousands of Nepali and more than 4 million work permits have been granted since 2008/2009 for work-related international migration to countries other than India. ${ }^{8}$ Citizens of Nepal and India do not require a labor permit to work in each other's country. The most recent Nepal Demographic and Health Survey 2016 showed that 47\% of the Nepali households had at least one migrant member in the family in the last decade. ${ }^{9}$ According to the Nepal Labor Migration Report 2020, Nepali labor migrants are mostly males, low-skilled, the vast majority work in Gulf Cooperation Council (GCC) countries and Malaysia and had sent over US\$ 8.8 billion of remittance home in the year 2018/19. ${ }^{8}$

Nepali media often report a high prevalence of kidney failure in returnee Nepali migrant workers from GCC and Malaysia. ${ }^{10,11}$ It is unknown if these higher rates of kidney health-related problems are due to the natural rise in number in a country with a huge number of the population migrated for work or whether there is an increased risk compared to the general Nepali population due to the working and living conditions in abroad. Medical treatment of kidney health-related problems in Nepal is limited and expensive, especially in endstage renal disease, where renal replacement therapies in the form of dialysis or renal transplantation are the only specific measures of management. This has huge financial implication to their family and could push them towards poverty.

In the recent years, the evidence is emerging that chronic or repeated episodes of heat stress accompanied by strenuous work and dehydration may trigger pre-renal acute kidney injury (AKI) that might eventually progress to $\mathrm{CKD} .{ }^{12}$ This phenomenon has been mainly attributed to disproportionately higher $\mathrm{CKD}$ rates in agriculture workers in Central America, America, India, Sri Lanka, Thailand, and in other countries. ${ }^{13}$ The vast majority of migrant workers in the countries of the Gulf and Malaysia work in searing heat with intense physical exertion with less opportunity of regular rehydration. ${ }^{14}$ Thus, we speculate that this working condition may expose them to a higher risk of kidney injuries and subsequent $\mathrm{CKD}$.

There is no reporting system to understand the health issues of returnee migrants in Nepal nor do hospitals keep a record of their patients by migrant status. Though many studies among Nepali migrants report wide-ranging health and wellbeing issues, ${ }^{15,16}$ none of them reported the kidney health-related problems while abroad or after their return.

\section{Aims and objectives}

This study aims to (a) explore the magnitude of the kidney health-related problems in returnee Nepali migrant workers; and, (b) assess the need for further scientific investigations.

\section{MATERIALS AND METHODS}

This was a self-administered online survey among nephrologists of Nepal.

\section{Respondents}

The study population was the entire group of nephrologists of Nepal. There were 51 members in the Nepal Society of Nephrology at the time of this study. Inclusion criteria were nephrologists currently practicing in Nepal, had Internet access, and could be contacted through email.

\section{Questionnaire}

A questionnaire was developed by study team members based on the literature review and by consulting with migrant and kidney health-related experts (Supplemental 1). It included 23 questions consisting of closed-ended, free-text, and questions with multiple responses. The questions included the socio-demographic characteristics of returnee migrant workers, their major destination countries and occupation, specific kidney-related problems returnee migrants usually have and possible causes, risk of kidney-related problems of returnee migrant compared to general Nepali population, and need for further research. Respondents were asked to provide this information based on their general experience and communication with returnee migrants during medical treatment. A questionnaire was pre-tested ${ }^{17}$ among four nephrologists who were excluded from further participation to avoid contamination of the study sample.

\section{Data collection and analysis}

The JISC online survey platform (www.onlinesurveys. ac.uk) was used to design the survey contents. The survey weblink and participant information sheet were provided for anonymous participation. Since this was a self-administered online survey, participation in the survey meant providing consent for the study. One of the authors (AS), a practicing Nepali nephrologist, contacted colleagues in Nepal through social media and by email and phone to encourage them to participate in the study. Data were collected between December 2019 and February 2020. Descriptive statistics were generated using the mean, standard deviation (SD), range, frequency, and percentages using STATA software version 14 (Stata Corporation, College Station, TX, USA). 


\section{Ethical considerations}

Ethical approvals were sought from the Nepal Health Research Council (reference number 1199/2019), a government ethical clearance body for health research in Nepal, and Research Ethics Committee of Bournemouth University (reference number 23986).

\section{RESULTS}

A total of 38 nephrologists responded to this online survey. Assuming that the survey has reached to all study population excluding four who participated in a pilot survey (i.e. 47 of 51 nephrologists), the response rate was $80.8 \%$.

\section{Characteristics of respondents}

Most respondents $(84.2 \%, \mathrm{n}=32)$ were male, from Kathmandu district, and based in four of the seven provinces of Nepal. They worked as a nephrologist for a minimum of two to a maximum of 34 years. The mean number of patients they saw daily was 22 (SD 11.8, range 10-75). Responding nephrologists reported that of all patients they saw daily, on average $1.7 \%$ (SD 2.9, range 0.1-15) were returnee migrant workers and this was highest in Morang district (10\%). Table 1 shows the sociodemographic characteristics of responding nephrologists.

Respondents' experience with returnee migrant patients

Almost all their migrant patients were younger than 40 years, male, from rural areas of Nepal, and had worked in GCC countries and Malaysia (Table 2). Twenty-six out of 37 respondents $(70.3 \%)$ reported that their migrant

\begin{tabular}{lc}
\multicolumn{2}{l}{ Table 1: Sociodemographic characteristics of } \\
the responding nephrologists (N=38) \\
\hline Continuous variables & Mean (SD) \\
\hline Age (years) & $43.8(7.2)$ \\
Working period as a nephrologist (years) & $8.9(7.4)$ \\
\hline Categorical variables & Number (\%) \\
\hline Sex & $32(84.2)$ \\
Male & $6(15.8)$ \\
Female & \\
Place of practice (district) & $27(71.0)$ \\
Kathmandu & $3(7.9)$ \\
Rupandehi & $2(5.3)$ \\
Chitwan & $2(5.3)$ \\
Kaski & $2(5.3)$ \\
Lalitpur & $1(2.6)$ \\
Sunsari & $1(2.6)$ \\
Morang & \\
Types of health facility & $11(28.9)$ \\
Private hospital or clinic & $5(13.2)$ \\
Public hospital or clinic & $22(57.9)$ \\
Both private and public & \\
\hline
\end{tabular}

patients were involved in an outdoor job while abroad, however, they did not know their patients' occupation. Most respondents $(68.4 \%, \mathrm{n}=26)$ reported they did not know if their migrant patients had the kidney problems before they went for employment, however, two (5.3\%) reported that proteinuria was diagnosed in migrant patients before they went abroad for work.

Figure 1 shows that CKD and glomerulonephritis were the most common kidney problems of returnee migrant workers according to nephrologists. Most (92.1\%, n=35) respondents reported that the causes behind kidney-related problems of returnee migrant workers were of unknown etiology, and the rest related to traditional risk factors (e.g. diabetes, hypertension).

\section{Table 2: Respondents' experience with returnee migrant patients $(\mathrm{N}=38)$}

\begin{tabular}{|c|c|}
\hline Variables & Number (\%) \\
\hline \multicolumn{2}{|c|}{$\begin{array}{l}\text { Most common age group of migrant patients } \\
\text { (years) }\end{array}$} \\
\hline $20-29$ & $11(28.9)$ \\
\hline $30-39$ & $9(23.7)$ \\
\hline 20-29 and 30-39 & $17(44.7)$ \\
\hline $20-29,30-39$ and $40-50$ & $1(2.6)$ \\
\hline \multicolumn{2}{|l|}{ Most common sex of migrant patients } \\
\hline Male & $37(97.4)$ \\
\hline Male and female equally & $1(2.6)$ \\
\hline \multicolumn{2}{|c|}{$\begin{array}{l}\text { Most common living areas of migrant patients (in } \\
\text { Nepal) }\end{array}$} \\
\hline Rural & $29(76.3)$ \\
\hline Urban & $7(18.4)$ \\
\hline Do not know & $2(5.3 \%)$ \\
\hline \multicolumn{2}{|c|}{ Major work destination of migrant patients* } \\
\hline Gulf & $16(42.1)$ \\
\hline Gulf and Malaysia & $16(42.1)$ \\
\hline Gulf, Malaysia, and Korea & $4(10.5)$ \\
\hline Gulf, Malaysia, and India or Korea & $2(5.3)$ \\
\hline \multicolumn{2}{|l|}{ Type of work of migrant patients $(\mathrm{N}=37)$} \\
\hline Outdoor & $26(70.3)$ \\
\hline Indoor & $1(2.7)$ \\
\hline Do not know & $10(27.0)$ \\
\hline \multicolumn{2}{|c|}{ Are migrant patients from a specific ethnicity? } \\
\hline Yes & $0(0)$ \\
\hline No & $13(34.2)$ \\
\hline Do not know & $25(65.8)$ \\
\hline \multicolumn{2}{|c|}{$\begin{array}{l}\text { Are migrant patients with kidney problems have a } \\
\text { specific occupation? }(n=37)\end{array}$} \\
\hline Yes & $5(13.5)$ \\
\hline No & $5(13.5)$ \\
\hline Do not know & $27(73.0)$ \\
\hline \multicolumn{2}{|c|}{$\begin{array}{l}\text { The kidney problem of migrant patients is prior to } \\
\text { working abroad }\end{array}$} \\
\hline Yes & $3(7.9)$ \\
\hline No & $9(23.7)$ \\
\hline Do not know & $26(68.4)$ \\
\hline
\end{tabular}




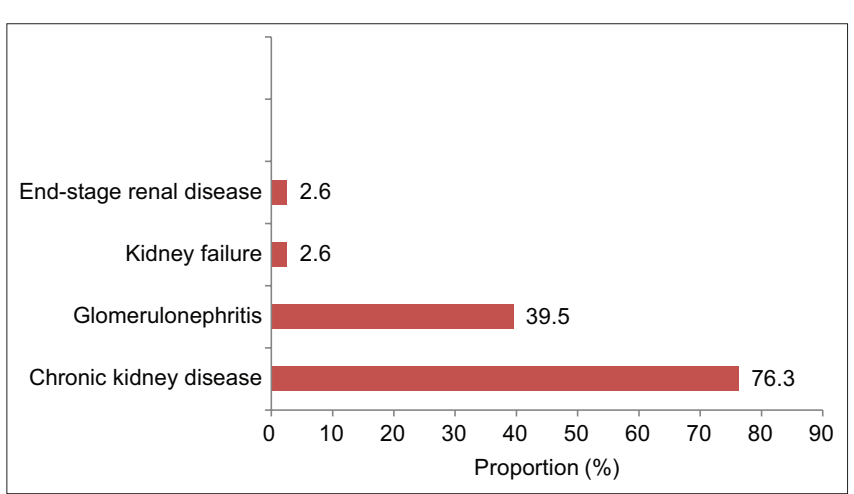

Figure 1: Percentage of kidney problems of returnee labor migrants reported by nephrologists in Nepal (multiple responses possible) ( $\mathrm{N}=38$ )

Respondents predicted the following possible risk factors for the kidney-related problems on returnee migrant workers:

(i) Dehydration

(ii) Use of salty and fizzy drinks and excessive protein intake (e.g. meat)

(iii) Heavy physical work

(iv) Use of painkillers (non-steroidal anti-inflammatory drugs)

(v) Lack of regular health check-up.

Twenty-three $(60.5 \%)$ respondents reported that they had ever treated migrant patients who were returned back to Nepal only because of kidney-related problems. On average this number of patients was 7.7 (SD 7.6, range 1-30).

The majority $(76.3 \%, \mathrm{n}=29)$ of respondents thought that the returnee migrant workers are at a higher risk of kidneyrelated problems than general Nepali population; less than one-quarter $(21.1 \%, \mathrm{n}=8)$ were uncertain and one $(2.6 \%)$ disagreed. All respondents agreed that kidney health-related problems in returnee Nepali migrant workers warrant further scientific research to understand the magnitude of the problem.

Some important free-text responses from the respondents include:

- Some of the migrant patients are aware that working in GCC countries may damage their kidneys (Respondent 5)

- Needs detailed research in large scales to explore the magnitude of the problem (Respondent 7)

- Need more awareness and better screening before going abroad (Respondent 8)

- Screening of toxins and heavy metals could be important (Respondent 11)

- Nephrologists should be involved in pre-migration health screening (Respondent 15).

\section{DISCUSSION}

The present study on Nepal-based nephrologists which is the first of its kind suggests that returnee migrant workers could be at higher risk of kidney-related problems than the general Nepali population. Returnee migrant workers with kidney-related issues were usually male, aged 40 years or below, had worked in GCC countries and Malaysia, and hailed from rural areas of Nepal. The vast majority nephrologists reported that the causes behind the kidneyrelated problems were of unknown etiology and perhaps less likely to be caused by traditional risk factors (e.g. diabetes, hypertension).

The kidney health risk of low-skilled male migrant workers from Asia in the countries of the GCC and Malaysia are beginning to draw scientific attention. ${ }^{18} \mathrm{~A}$ longitudinal study among Indian construction workers in Saudi Arabia suggested that exposure to heat stress, long working hours, dehydration, sleep deprivation, and obesity may induce the risk to kidney health in workers. ${ }^{19}$ In Ponorogo district of Indonesia, $18 \%$ of the patients with chronic renal failure were former migrant workers. ${ }^{20} \mathrm{~A}$ qualitative study among Indonesian migrant workers with CKD reported that they were also involved in unhealthy eating, such as a high intake of alcohol and soft drinks and high consumption of fast food. ${ }^{21} \mathrm{~A}$ global systematic review reported that $15 \%$ of individuals working in extreme heat had kidney disease and injuries which is significantly higher than that of the general population living in high-income and low-income countries. ${ }^{22}$

In the present study, $92.1 \%$ of the respondents reported that the causes for kidney-related problems among returnee migrant workers were of unknown etiology and the most common risk factors for kidney-related problems (such as diabetes, hypertension) were usually absent. These indicate occupational renal risk of low-skilled Nepali migrant workers abroad. A similar pattern of the risk factors for kidney health was also observed among farmworkers in Central America. ${ }^{23}$

It has been speculated that a number of Nepali migrants return back to Nepal each year due to the kidney-related problems. ${ }^{10,11}$ The Nepali Embassy in a key migrant destination country also acknowledges the rising cases of kidney-related problems among migrant workers. ${ }^{18}$ Our findings also support this as nearly two-thirds of the respondents had ever treated migrant patients who were returned to Nepal only due to kidney-related problems. As patients show no symptoms, kidney-related problems are hard to diagnose in the early stages. Patients usually seek medical advice when the damage is already done and not possible to reverse. ${ }^{24}$ 
In April 2019, two of the authors (NA and PRR) carried out a patient public involvement event in Malaysia regarding kidney health-related issues of Nepali migrants. ${ }^{18}$ Participating Nepali migrants shared some work-related circumstances which might precipitate risk to their kidney health. For example, migrant workers in the manufacturing sectors have a fixed schedule for going to the bathroom or having a drink because the manufacturing process can get disrupted in the absence of one worker. ${ }^{18}$ There was also a concern of unavailability of potable water in many manufacturing sites in Malaysia, Nepali migrant workers frequently use a high dose of painkillers because they work continuously for several weeks without a day off, and security guards are allowed to use the toilet just twice a day due to the lack of replacement guards which force them to drink a little amount of water throughout the long work shift. ${ }^{18}$

CGN has been found to be one of the commonest causes of CKD in Nepal. The earliest presentation of glomerulonephritis is asymptomatic hematuria and or hematuria, which can be easily detected by a routine urine test. If detected and treated early, most of the glomerulonephritis-associated CKD can be prevented. Although the general health check-up of the people going abroad as a migrant worker is mandatory in Nepal, at times the urinary findings, that could be clinically significant, might be overlooked. In the present study, glomerulonephritis has been reported as one of the key kidney health problems among returnee migrants. This warrants further improvements in the screening and early detection of this correctable renal entity not only before going abroad but also on a routine basis during their stay and working period in foreign countries.

Although there is limited evidence on kidney health-related risk among migrant workers, there is a preponderance of evidence in the last two decades regarding the markedly higher risk of CKD among farmworkers in Central America, Sri Lanka, Egypt, and in India. ${ }^{23}$ This is often termed as "mesoamerican nephropathy" 25 or CKD with unknown aetiology. ${ }^{23}$ The working conditions of these farmers and the majority of Asian migrant workers in GCC countries and Malaysia are largely similar, such as performing physically demanding work in a hot environment with recurrent dehydration. ${ }^{19,26}$ There is evidence that the odds of AKI increased by $47 \%$ for each 5-degree Fahrenheit increment in the heat index, ${ }^{26}$ and a heavy workload was associated with detrimental effects on kidney health, ${ }^{27}$ and AKI was also observed among wellhydrated sugarcane workers in Guatemala. ${ }^{28}$ These may contribute to kidney injuries individually or in combination.

There is some evidence that the simple intervention to prevent kidney damage could be effective, such as the implementation of water, rest, shade program in the United States of America positively influenced the biomarkers of kidney function. ${ }^{24}$ Similar intervention could be carefully planned in the countries (e.g. Gulf, Malaysia) with a large number of labor migrants who often perform heavy physical work in heat stress.

This study assesses the need for large-scale studies on the kidney health risk of Nepali migrant workers. Although this was an online survey with nephrologists in Nepal, we were able to include more than three-quarters of its community.

\section{Limitations of the study}

This survey was limited by the non-participation of nephrologists currently working in the mid-western and far-Western part of the country. Seasonal migration to India is common in these regions, thus, the kidney health risk of Nepali cross border migrants in India is likely to be under-reported.

Also, the results might be prone to bias because this is dependent on nephrologists' recall of their migrant worker patients.

\section{CONCLUSION}

The present study shows that Nepali migrant workers, particularly males and those working in GCC countries and Malaysia, could be at higher risk of kidney health-related problems than the general Nepali population. CKD and glomerulonephritis were indicated as the most common kidney health-related problems in Nepali returnee migrants. Dehydration, heavy physical work, heat exposure, use of pain killers were suggested as potential risk factors. All respondent nephrologists believed that further scientific investigation is required to ascertain the magnitude of kidney health issues of Nepali migrants. Kidney function test is included in pre-departure health screening of Nepali labor migrants, however, the aspect of proper implementation is questionable. We highly recommend to the Department of Foreign Employment (Ministry of Labour) in Nepal to strictly monitor the implementation of pre-departure health screening. We also urge to include kidney health-related content in pre-departure orientation curriculum for aspiring migrant workers.

\section{ACKNOWLEDGMENTS}

We would like to acknowledge Jhabindra Bhandari (International Organization for Migration Nepal) for his significant contribution to questionnaire design as well as four Nepal-based nephrologists who participated in the piloting of the questionnaire. 


\section{REFERENCES}

1. El Nahas AM and Bello AK. Chronic kidney disease: The global challenge. Lancet. 2005;365(9456):331-340.

https://doi.org/10.1016/S0140-6736(05)17789-7

2. Correa-Rotter R, Naicker S, Katz IJ, Agarwal SK, Valdes RH, Kaseje D, et al. Demographic and epidemiologic transition in the developing world: Role of albuminuria in the early diagnosis and prevention of renal and cardiovascular disease. Kidney Int. 2004;92:S32-S37.

https://doi.org/10.1111/j.1523-1755.2004.09208.x

3. Hill NR, Fatoba ST, Oke JL, Hirst JA, O'Callaghan CA, Lasserson DS, et al. Global prevalence of chronic kidney disease a systematic review and meta-analysis. PLoS One. 2016;11(7):e0158765.

https://doi.org/10.1371/journal.pone.0158765

4. Luyckx VA, Tonelli M and Stanifer JW. The global burden of kidney disease and the sustainable development goals. Bull World Health Organ. 2018;96(6):414-422D.

https://doi.org/10.2471/BLT.17.206441

5. Nepal Health Research Council. Population Based Prevalence of Selected Non-Communicable Diseases in Nepal. Kathmandu, Nepal: Nepal Health Research Council; 2019.

6. Sharma SK, Dhakal S, Thapa L, Ghimire A, Tamrakar R, Chaudhary $S$, et al. Community-based screening for chronic kidney disease, hypertension and diabetes in Dharan. J Nepal Med Assoc. 2013;52(189):205-212.

7. Khakurel S, Agrawal RK and Hada R. Pattern of end stage renal disease in a tertiary care center. J Nepal Med Assoc. 2009;48(174):126-130.

8. Ministry of Labour, Employment and Social Security. Nepal Labour Migration Report 2020. 2020; Kathmandu, Nepal. Available from: https://moless.gov.np/wp-content/uploads/2020/03/MigrationReport-2020-English.pdf. [Last accessed on 2021 Jun 16].

9. Ministry of Health, New ERA, and ICF. Nepal Demographic and Health Survey 2016. 2017; Kathmandu, Nepal. Available from: https://www.dhsprogram.com/pubs/pdf/fr336/fr336.pdf. [Last accessed on 2021 Jun 16].

10. DhakalS. RenalFailureRampantamong Migrants. In:TheHimalayan Times; 2017. https://thehimalayantimes.com/nepal/renal-failurerampant-among-migrants. [Last accessed on 2021 Jun 16].

11. Rai O. A Mysterious Rash of Kidney Failures. In: Nepali Times; 2017. http://archive.nepalitimes.com/article/NepaliTimes-Buzz/A-mysterious-rash-of-kidney-failures, 3639. [Last accessed on 2021 Oct 10].

12. Nerbass FB, Pecoits-Filho R, Clark WF, Sontrop JM, McIntyre CW and Moist L. Occupational heat stress and kidney health: from farms to factories. Kidney Int Reports. 2017;2(6):998-1008.

https://doi.org/10.1016/j.ekir.2017.08.012

13. Glaser J, Lemery J, Rajagopalan B, Diaz HF, García-Trabanino R, Taduri G, et al. Climate change and the emergent epidemic of CKD from heat stress in rural communities: The case for heat stress nephropathy. Clin J Am Soc Nephrol. 2016;11(8):1472-1483.

https://doi.org/10.2215/CJN.13841215

14. Adhikary $P$, Keen $S$ and van Teijlingen E. Workplace accidents among Nepali male workers in the Middle East and Malaysia: A qualitative study. J Immigr Minor Health. 2019;21(5):1115-1122.

https://doi.org/10.1007/s10903-018-0801-y

15. Paudyal $P$, Kulasabanathan K, Cassell JA, Memon A, Simkhada $P$ and Wasti SP. Health and well-being issues of Nepalese migrant workers in the Gulf Cooperation Council countries and Malaysia: A systematic review. BMJ Open. 2020;10(10):e038439.

http://dx.doi.org/10.1136/bmjopen-2020-038439

16. Simkhada PP, Regmi PR, van Teijlingen E and Aryal N. Identifying the gaps in Nepalese migrant workers' health and well-being: A review of the literature. J Travel Med. 2017;24(4):21. https://doi.org/10.1093/jtm/tax021

17. Regmi PR, Waithaka E, Paudyal A, Simkhada $P$ and van Teijlingen E. Guide to the design and application of online questionnaire surveys. Nepal J Epidemiol. 2016;6(4):640. http://doi.org/10.3126/nje.v6i4.17258

18. Aryal N, Regmi PR, Faller EM, van Teijlingen E, Khoon CC, Pereira A, et al. Sudden cardiac death and kidney health related problems among Nepali migrant workers in Malaysia. Nepal J Epidemiol. 2019;9(3):788-791. http://doi.org/10.3126/nje.v9i3.2580510.3126/nje.v9i3.25805

19. Al-Bouwarthan M, Quinn MM, Kriebel D and Wegman DH. Risk of kidney injury among construction workers exposed to heat stress: A longitudinal study from Saudi Arabia. Int J Environ Res Public Health. 2020;17(11):3775. https://doi.org/10.3390/ijerph17113775

20. Isroin L. Heavy Activity Risks Chronic Renal Failure. Pros International Joint Conference; 2015.

21. Isroin L. Behavioral impact on kidney function among indonesian migrant workers. Kesmas Natl Public Health $\mathrm{J}$. 2018;2:e521-e531.

http://journal.fkm.ui.ac.id/kesmas/article/view/2720

22. Flouris $A D$, Dinas $P C$, loannou LG, Nybo L, Havenith $G$, Kenny GP, et al. Workers' health and productivity under occupational heat strain: A systematic review and meta-analysis. Lancet Planet Health. 2018;2:e521-e531.

https://doi.org/10.1016/S2542-5196(18)30237-7

23. Weaver VM, Fadrowski JJ and Jaar BG. Global dimensions of chronic kidney disease of unknown etiology (CKDu): A modern era environmental and/or occupational nephropathy? BMC Nephrol. 2015;16:145.

https://doi.org/10.1186/s12882-015-0105-6

24. Broberg K. Water, rest, shade: Can simple actions stop an epidemic of chronic kidney disease of unknown etiology among farm workers in Central America? Scand J Work Environ Health. 2018;44(1):1-2. https://doi.org/10.5271/sjweh.3699

25. Kupferman J, Ramírez-Rubio O, Amador JJ, López-Pilarte D, Wilker EH, Laws RL, et al. Acute kidney injury in sugarcane workers at risk for Mesoamerican nephropathy. Am J Kidney Dis. 2018;72(4):475-482. https://doi.org/10.1053/j.ajkd.2018.04.014

26. Mix J, Elon L, Vi Thien Mac V, Flocks J, Economos E, TovarAguilar AJ, et al. Hydration status, kidney function, and kidney injury in florida agricultural workers. J Occup Environ Med. 2018;60(5):e253-e260. https://doi.org/10.1097/JOM.0000000000001261

27. Moyce S, Armitage T, Mitchell D and Schenker M. Acute kidney injury and workload in a sample of California agricultural workers. Am J Ind Med. 2020;63(3):258-268. https://doi.org/10.1002/ajim.23076

28. Butler-Dawson J, Krisher L, Asensio C, Cruz A, Tenney L, Weitzenkamp D, et al. Risk factors for declines in kidney function in sugarcane workers in Guatemala. J Occup Environ Med. 2018;60(6):548-558. https://doi.org/10.1097/JOM.0000000000001284 


\section{Authors' Contributions:}

NA, PRR- Conceived the study; AS- Co-ordinated for data collection in Nepal. All authors contributed to the questionnaire design; NA-Analysed the data and wrote the first draft of the manuscript; All authors helped with the revision of the manuscript and agreed on the final version

Work attributed to:

Bournemouth University, UK; Chitwan Medical College, Tribhuvan University, Nepal; International Organization for Migration, Nepal

\section{ORCID ID:}

Nirmal Aryal- (i) https://orcid.org/0000-0002-4835-0785

Arun Sedhain- (D) https://orcid.org/0000-0003-2590-9096

Pramod R Regmi- (i) https://orcid.org/0000-0003-0226-3894

Radheshyam Krishna KC- (1) https://orcid.org/0000-0002-8302-4491

Edwin van Teijlingen- (iD) https://orcid.org/0000-0001-5523-8583

Source of Funding: Funding is not required for this online survey. However, Bournemouth University, UK paid for an ethical approval cost in Nepal, Conflicts of Interest: None. 